\title{
Training in colorectal surgery in Europe and 20 years of the European Board of Surgical Qualification coloproctology examination
}

\author{
H. Teixeira Farinha*, K. E. Matzel†', J. Nichollsł, F. Hetzer§, D. D. E. Zimmermanף (D), \\ J. Warusavitarne** and D. Hahnloser* \\ *Department of Visceral Surgery, University Hospital CHUV, Lausanne, Switzerland, †Department of Visceral Surgery, University of Erlangen, Erlangen, \\ Germany, \$Department of Surgery and Cancer, Imperial College London, St Mark's Hospital, London, UK, §Bellaria Chirurgie, Zurich, Switzerland, \\ qDepartment of Surgery, ETZ (Elisabeth - TweeSteden Ziekenhuis) Hospital, Tilburg, The Netherlands, and ***Department of Surgery, St. Mark's \\ Hospital, London, UK
}

Received 14 October 2019; accepted 15 December 2019; Accepted Article online date 27 January 2020

\begin{abstract}
Aim Training in colorectal surgery across Europe is not yet standardized. The European Board of Surgical Qualification (EBSQ) coloproctology examination has been held annually since 1998. The aims of this study were to illustrate the current situation of coloproctology specialization in Europe and to analyse the EBSQ examinations held over the last 20 years.
\end{abstract}

Method A survey, focused on current training and education in colorectal surgery in Europe, was conducted among all national representatives of the European Society of Coloproctology (ESCP) in 2018. Candidate demographics (1998-2018) and the results of the EBSQ examination (2007-2018) were analysed.

Results In Europe, there are currently 26 national colorectal societies, 27 national annual colorectal meetings, 16 national specialized training programmes and 13 national colorectal fellowships. Six countries have board certification in colorectal surgery and five a dedicated examination. During the last 20 years, 475 candidates from 29 countries, of whom 88 (19\%) were women, passed the EBSQ examination. The pass rate was higher in younger applicants $(<42$ years, $P=0.01)$. The success rate was higher for candidates with academic experience (more than five publications or presentations) and with an academic title (thesis) $(P=0.01)$.

Conclusion Colorectal surgical training is still not standardized in Europe, although efforts have been made to recognize colorectal surgery as an independent speciality. The number of holders of the EBSQ Diploma has increased over the years, demonstrating the acceptance of the examination among European surgeons. Young candidates with an academic profile are the most successful.

Keywords Colorectal surgery, surgical education, training, EBSQ

\section{What does this paper add to the literature?}

This paper illustrates the current situation of specialization in coloproctology in Europe and is the only paper to analyse the results of the European Board of Surgical Qualification coloproctology examination over the last 20 years.

\section{Introduction}

In many countries in Europe, the majority of colorectal interventions are performed by general surgeons. Colorectal surgery is not recognized as a speciality nor

Correspondence to: D. Hahnloser, Department of Visceral Surgery, University Hospital CHUV, I0II Lausanne, Switzerland.

E-mail: dieter.hahnloser@chuv.ch

Meeting presentations: these results were presented at the ESCP Annual Meeting, 27 September 2018 in Nice, France. is it certified. In addition, colorectal surgery training across Europe is variable, not standardized and is delivered through a wide range of different systems [1].

The Union Européenne des Médecins Spécialistes (UEMS) was founded in 1958 to promote the interests of specialists in all medical disciplines. The European Board of Surgery (EBS) was formed by the UEMS to develop an accreditation and certification diploma in general surgery, which became known as the European Board of Surgical Qualification (EBSQ 
Gen). Since 1998, coloproctology has been a recognized speciality within the Section of Surgery and became the Division of Coloproctology. The first EBSQ (Coloproctology) diplomas were awarded in 1998 and their subsequent uptake demonstrates increasing interest in specialization in colorectal surgery in Europe $[2,3]$.

The examination for the EBSQ (Coloproctology) diploma is open to all surgeons with a colorectal interest currently working or trained in a UEMS or UEMS-affiliated country. Briefly, it consists of two parts. Part 1 assesses eligibility to take the examination based on at least 2 years of specialist colorectal training and the number of interventions performed by the applicant (https://www.uemssurg.org/divi sions/coloproctology). These are divided into five indicator procedures: anterior resection, rectal prolapse procedures, total colectomy, haemorrhoidectomy, stoma formation and fistula procedures. Part 2 is the actual examination and includes a written analysis with an evolving case (written part), followed by an oral discussion of a peer-reviewed article (academic part) and an oral discussion of 10 short clinical cases (general part). The EBSQ examination covers the entire field of coloproctology including cancer, inflammatory bowel disease, proctology and functional disorders $[3,4]$. The current total cost for the EBSQ coloproctology examination is $€ 700$, similar to all other EBSQ examinations of the UEMS.

The pass rates were set in 1998. To be successful, a candidate needs to obtain a total mark of $66 \%$ from the combined written, academic and general parts of the examination, together with a mark of at least $60 \%$ in each section of the examination. The written part counts as double the weight of the academic or general part.

The candidate is examined by three pairs of examiners to cover the three parts. The examining board is composed of senior surgeons who come from any of the member states included in the UEMS. Every examiner must have obtained the EBSQ Diploma. He or she can be an examiner after a minimum of 3 years since passing the examination. The examiners must have no personal knowledge of the candidate and should be from a different country if possible. There are five official languages in the European Union and the candidate can choose whichever he or she wishes to be examined in. Only occasionally will this require the assistance of an interpreter.

The aims of the study were to assess the current situation of specialization in coloproctology in Europe and to analyse the results of the EBSQ (Coloproctology) examination over the last 20 years.

\section{Method}

\section{Current colorectal training in Europe}

In 2018 a survey (Appendix S1 in the online Supporting Information) was sent to all 32 national representatives of the ESCP Council. The ESCP is divided into three regions: central Europe (Austria, Czech Republic, Denmark, Germany, Hungary, Italy, Slovenia, Sweden, Switzerland), eastern Europe (Azerbaijan, Bulgaria, Egypt, Finland, Greece, Israel, Latvia, Lithuania, Poland, Romania, Russia, Serbia, Turkey, Ukraine) and western Europe (Belgium, France, Iceland, Ireland, Norway, Portugal, Spain, Netherlands, UK). The survey required information on the following items: the existence of a national colorectal society and/or an annual national colorectal meeting, the minimum number of years dedicated to colorectal training, the existence of a national specialized training programme and/or colorectal fellowships and national board certification in colorectal surgery including a dedicated examination.

A national specialized training programme is defined by the existence of a training programme dedicated to colorectal surgery organized by a national colorectal society or by a national general surgical society. This must include training posts in a colorectal surgical department, excluding fellowships sponsored by industry or local fellowships confined to one hospital.

\section{Candidates for the EBSQ examinations}

The UEMS provided the number of EBSQ fellows and their country of origin seeking accreditation and certification in all available surgical disciplines from 1997 to 2018. Information on demographics, surgical training and academic expertise of all eligible candidates was available from 2007 to 2018. Demographics (age, gender, origin), surgical training (surgical years, dedicated colorectal surgical years, number and type of surgical interventions), academic expertise (number of scientific publications and oral presentations, theses) were included in the analysis. Data were received and analysed anonymously [5].

\section{Results of the EBSQ examinations}

The pass rate from 2007 to 2011 was provided by the UEMS. From 2011 to 2018 , detailed data on all three parts of the examination (written, general and academic) were provided by the Division of Coloproctology of the Section of Surgery of the UEMS. All data on the candidates and their examination results were entered retrospectively onto a database. 


\section{Statistical analysis}

Descriptive statistics for categorical variables were reported as frequency (\%), while continuous variables were reported as median (interquartile range, IQR). The chisquare test was used for comparison of categorical variables and the Wilcoxon test for continuous data. All statistical tests were two-sided and a probability level of 0.05 was used to indicate statistical significance. Data analysis was performed using SPSS, v.25.0 (SPSS Inc., IBM Corp, Armonk, NY, USA). Graphics were designed using GraphPad Prism software, v.7 (GraphPad Software, La Jolla, CA, USA).

\section{Results}

Despite being sent three reminders, three national representatives did not respond to the survey, giving an overall response of $29(91 \%)$ out of 32 [4].

\section{Current colorectal training in Europe}

Data were available for 29 countries. Of these 26 (90\%) had a colorectal society, $22(76 \%)$ had an annual colorectal congress and 5 (17\%) had a colorectal component as part of an annual general surgical meeting. Sixteen $(55 \%)$ countries had a specialized training programme. A fellowship in colorectal surgery was currently available in 13 (45\%) countries, Spain and Turkey being the last two to have introduced a fellowship, both in 2015 (Fig. 1).

Only six $(21 \%)$ countries offered board certification in colorectal surgery, with five offering a dedicated examination. These could be practical and oral as in the Czech Republic, or only oral as in Israel. In the UK and Ireland, certification was in general surgery but included a specialist examination in coloproctology comprising oral, practical and multiple choice parts as
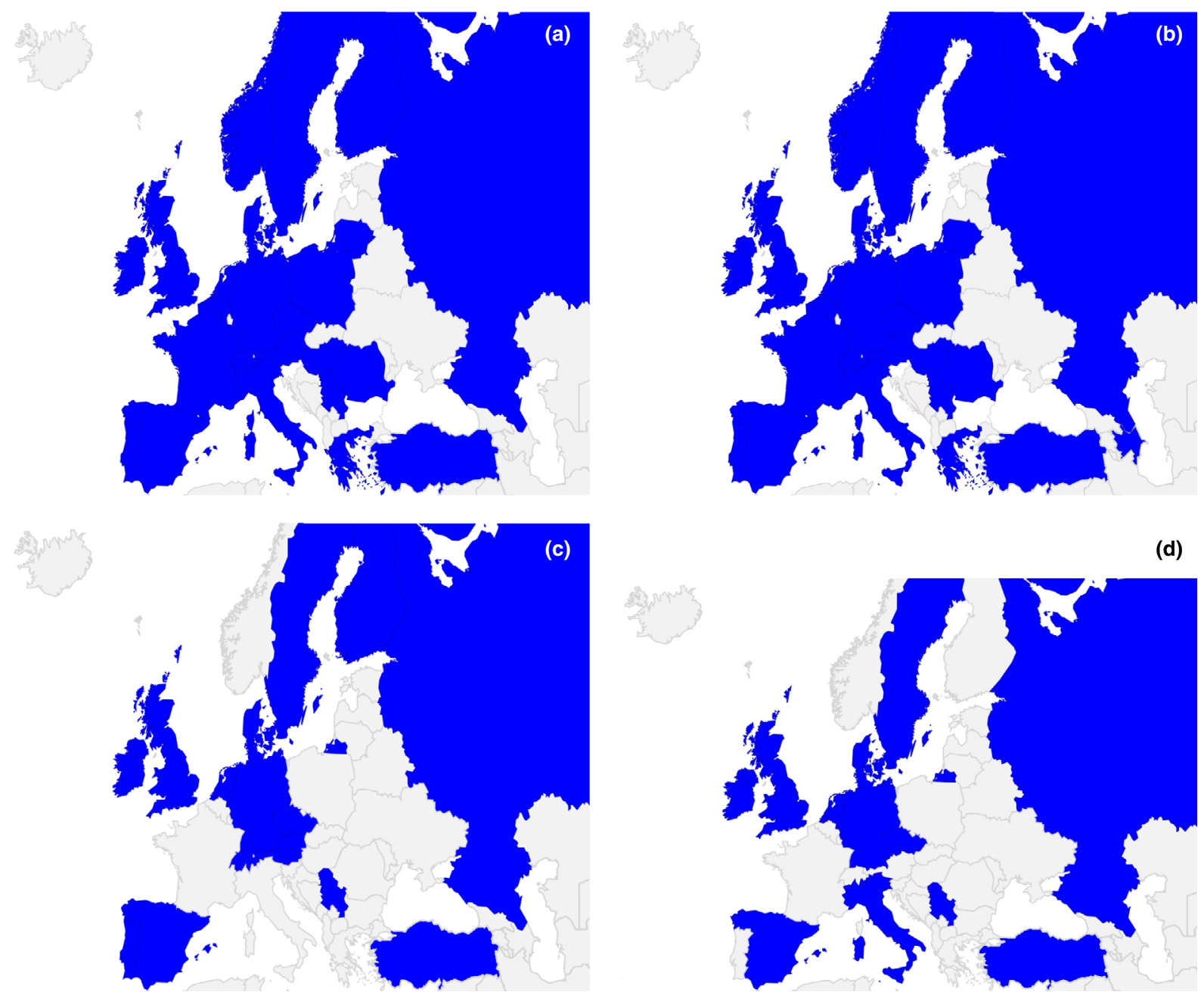

(c)

(d)

Figure I Colorectal training in Europe: (a) 26 colorectal societies, (b) 27 national annual colorectal meetings, (c) 16 national specialized training programmes and (d) 13 national fellowships. 
Table I Training in colorectal surgery in Europe by country.

\begin{tabular}{|c|c|c|c|c|c|}
\hline Country & $\begin{array}{l}\text { National } \\
\text { colorectal } \\
\text { society }\end{array}$ & Annual colorectal meeting & $\begin{array}{l}\text { Specialized } \\
\text { colorectal } \\
\text { training }\end{array}$ & $\begin{array}{l}\text { Colorectal } \\
\text { fellowship }\end{array}$ & $\begin{array}{l}\text { Board in } \\
\text { colorectal } \\
\text { surgery }\end{array}$ \\
\hline Austria & Yes & Part of general surgery & Yes & No & No \\
\hline Belgium & Yes & Independent & No & No & No \\
\hline Bulgaria & No & Independent & No & No & No \\
\hline Czech Republic & Yes & Independent & Yes & Yes & Yes \\
\hline Denmark & Yes & Part of general surgery & Yes & Yes & Yes \\
\hline Finland & Yes & Part of general surgery & Yes & No & No \\
\hline France & Yes & Independent & No & No & No \\
\hline Germany & Yes & Independent & Yes & Yes & Yes \\
\hline Greece & Yes & Independent & No & No & No \\
\hline Hungary & Yes & Independent & No & No & No \\
\hline Iceland & - & - & - & - & - \\
\hline Ireland & Yes & Independent & Yes & Yes & No \\
\hline Israel & Yes & Independent & Yes & Yes & Yes \\
\hline Italy & Yes & Independent & No & Yes & No \\
\hline Latvia & - & - & - & - & - \\
\hline Lithuania & Yes & Independent & No & No & No \\
\hline Netherlands & Yes & Part of general surgery & Yes & Yes & No \\
\hline Norway & Yes & Independent & No & No & No \\
\hline Poland & Yes & Independent & No & No & No \\
\hline Portugal & Yes & Independent & Yes & No & No \\
\hline Romania & Yes & Independent & No & No & No \\
\hline Russia & Yes & Part of general surgery & Yes & Yes & Yes \\
\hline Serbia & Yes & Independent & Yes & No & No \\
\hline Slovenia & No & No & No & No & No \\
\hline Spain & Yes & Independent & Yes & Yes & No \\
\hline Sweden & Yes & Independent & Yes & Yes & No \\
\hline Switzerland & Yes & Independent & Yes & No & No \\
\hline Turkey & Yes & Independent & Yes & Yes & \\
\hline Ukraine & - & - & - & - & - \\
\hline UK & Yes & Independent & Yes & Yes & No \\
\hline
\end{tabular}

well as analysis of a published article. Training in colorectal surgery by country is detailed in Table 1 .

\section{EBSQ in coloproctology: candidates and examination}

By the end of 2018, there were 475 individuals holding the EBSQ (Coloproctology) diploma from 29 different countries, 88 (19\%) of whom were women, with a median age (IQR) of $42(39-46)$ years. The number of diplomates has increased continually since 1998, with an annual maximum of 49 in 2012, as shown in Fig. 2. The country with the most diplomates was Germany, with $132(28 \%)$, followed by Spain, with 88 (18.5\%) and the UK with 52 (11\%) (Fig. 3). Ten non-European surgeons obtained the EBSQ (Coloproctology) diploma during a period of training in a European centre: two each from the United Arab Emirates and Qatar and one each from Australia, Iran, Japan, Mexico, Pakistan and Saudi Arabia. When the number of graduates is calculated per capita, Switzerland had the highest rate, with 6.2 per million inhabitants. Graduates per capita are displayed in Fig. 4.

Between 2007 and 2018, 505 candidates took the EBSQ examination, of whom 344 (68\%) were successful. Thirty-three $(10 \%)$ of those who were successful passed the examination on the second attempt and three $(0.6 \%)$ on the third. There was no significant difference between men and women among the successful candidates (M:F, 240:55 vs 122:24; successful versus unsuccessful, respectively). The pass rate was significantly higher in younger applicants [median age (IQR) 42 (38-46) years vs 43 (40-47) years; pass vs fail, respectively; $P=0.01]$. It was also higher in candidates with fewer years of experience in general surgery [median surgical years (IQR) 6 (5-8.5) years vs 7 (59.5 ) years; $P=0.04]$. No difference was found in the pass rate according to the number of years of experience in colorectal surgery [median colorectal surgical years 


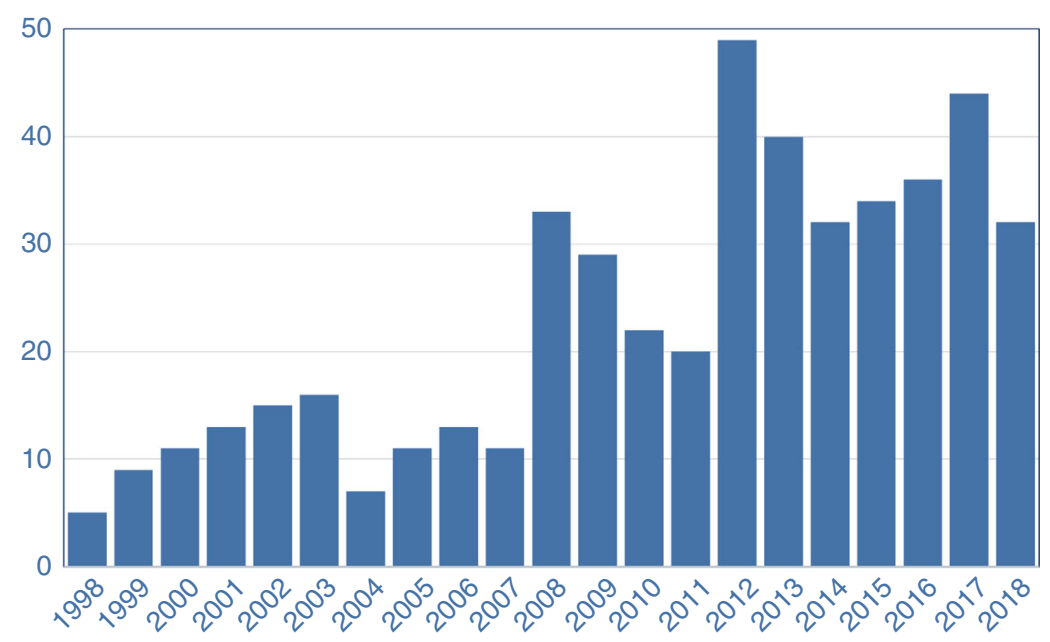

Figure 2 Annual numbers of EBSQ diplomates since 1998.

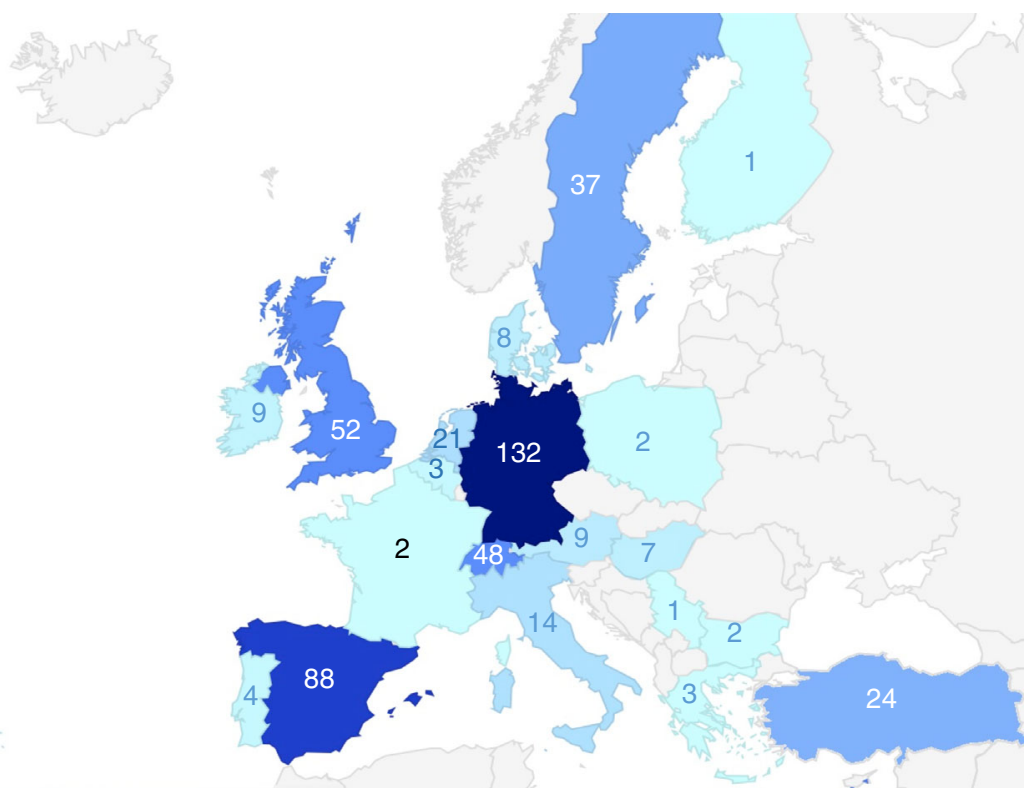

Figure 3 Number of ESCP diplomates per European country: Germany (132), Spain (88), UK (52), Switzerland (48), Sweden (37), Turkey (24), Netherlands (21), Italy (14), Austria (9), Ireland (9), Denmark (8), Hungary (7), Portugal (4), Belgium (3), Greece (3), Bulgaria (2), France (2), Poland (2), Finland (1).

(IQR) $4.3(4-7)$ years vs $5(3-8)$ years; $P=0.2)$ A detailed look at expertise in colorectal surgery, based on the five indicator procedures for the eligibility criteria (anterior resection, rectal prolapse procedures, total colectomy, haemorrhoidectomy and fistula procedures) did not show any difference between successful and unsuccessful candidates, except for a greater number of haemorrhoidectomies in relation to major procedures among failed applicants. In contrast, candidates with greater academic experience and those candidates having an academic title (with a thesis) had a significantly higher success rate $(P=0.01)$ (Table 2$)$.
The 344 candidates who passed the examination scored a median of $84 \%$ (IQR 76-91\%) of the possible points in the academic part, 83\% (IQR 73-90\%) in the general part and $71 \%$ (IQR 65-77\%) in the written part. Candidates with a thesis or an academic profile had a significantly higher score $(P<0.001)$. Older age was negatively correlated with the results $\left(X^{2}=-0.3285\right.$; $P<0.001)$. No other parameter in Part 1 correlated significantly with the results, including, in particular, the number of years spent in general or colorectal surgery or the number of operations performed. The written examination was the part that candidates failed most 


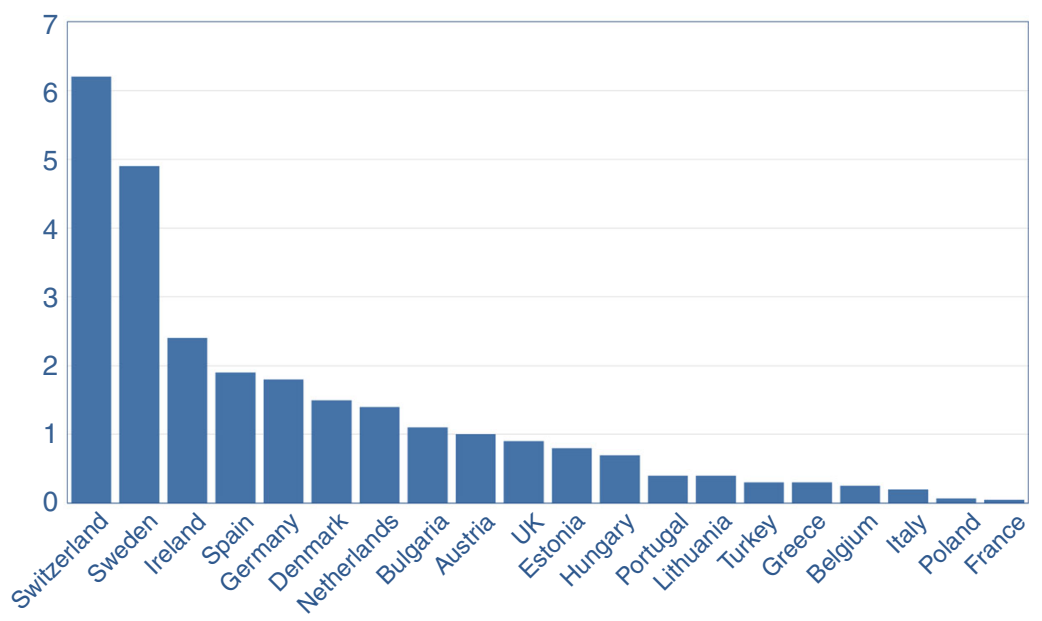

Figure 4 EBSQ diplomates since 1998 calculated as per million inhabitants.

Table 2 Surgical and academic experience and colorectal training between 2007 and 2018.

\begin{tabular}{lccc}
\hline & Passed & Failed & $P$-value \\
\hline Colorectal operations, median (IQR) & $739(521-1000)$ & $609(460-1037)$ & NSS \\
Anterior resection, median (IQR) & $48(27-82)$ & $50(25-85)$ & NS \\
Rectal prolapse procedure or total colectomy, median (IQR) & $20(13-42)$ & $24(12-50)$ & NS \\
Haemorrhoidectomy, median (IQR) & $58(30-119)$ & $79(35-150)$ & $\mathbf{0 . 0 2}$ \\
Fistula, median (IQR) & $56(32-95)$ & $\mathbf{5 8}(33-107)$ & NS \\
Five or more scientific publications, $n(\%)$ & $195(66 \%)$ & $91(62 \%)$ & $<0.01$ \\
Five or more scientific presentations, $n(\%)$ & $218(74 \%)$ & $69(47 \%)$ & $<0.01$ \\
Thesis, $n$ (\%) & $178(60 \%)$ & $143(97 \%)$ & NS \\
Colorectal training & & $144(97 \%)$ & NS \\
National colorectal society, $n(\%)$ & $280(95 \%)$ & $115(78 \%)$ & NS \\
Annual colorectal meeting, $n(\%) n$ & $279(95 \%)$ & $99(67 \%)$ & NS \\
Specialized colorectal training, $n(\%)$ & $174(74 \%)$ & $63(40 \%)$ & NS \\
Colorectal fellowship, $n(\%)$ & $86(30 \%)$ & & \\
Board in colorectal surgery, $n(\%)$ & & & \\
\hline
\end{tabular}

Bold Values: statistically significant $(P \leq 0.05)$.

frequently. Four failed because they did not reach $66 \%$ of the combined score from the sections despite reaching $60 \%$ in each individual section. The reasons for failure are shown in Table 3.

\section{The effect of a preparation course in Turkey}

In 2015 Turkey introduced a specialized colorectal course to prepare prospective candidates for the examination. Since then, the success rate among applicants from that country has improved significantly. Between 2007 and 2018, 34 candidates from Turkey had attempted the EBSQ coloproctology examination of whom $24(71 \%)$ passed; a rate considerably higher than that the $58 \%$ achieved up to 2014 . Of the 17 candidates taking the examination after 2015, 15 (88\%) were
Table 3 Reasons for failure between 2012 and 2017.

\begin{tabular}{lc}
\hline Reasons for failure $(n=75)$ & $n(\%)$ \\
\hline Written part only & $39(52 \%)$ \\
Academic part only & $7(8 \%)$ \\
General part only & $8(10 \%)$ \\
$66 \%$ rule only & $4(6 \%)$ \\
Written and academic & $6(8 \%)$ \\
Written and general & $8(10 \%)$ \\
Academic and general & $1(1 \%)$ \\
Written and academic and general & $2(3 \%)$ \\
\hline
\end{tabular}

successful $(P=0.05)$. There was also a correlation between the total number of colorectal operations and the pass rate in this cohort $\left(X^{2}=-0.5593 ; P=0.03\right)$ (Fig. 5). 


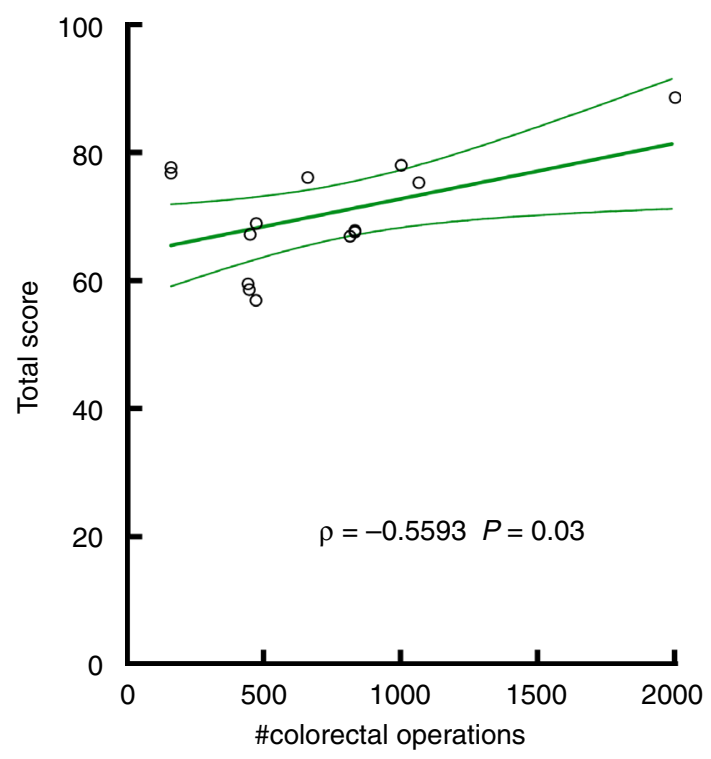

Figure 5 Correlation between the total number of colorectal operations and the scores in Turkey (2015-2018).

\section{Discussion}

Surgical training and education across Europe remains variable and nonstandardized, and colorectal surgery is not yet a certified subspeciality in many European countries. The vast majority of European countries, however, have progressively organized training in colorectal surgery, with structures ranging from national colorectal societies to colorectal board certification, as exemplified for example in Turkey. Several non-European countries such as the USA and Australia require credentialing to perform colorectal surgery, and this is carried out by national societies. These countries have often argued that credentialing provides better outcomes for patients, and in the USA in particular recertification every 5 years is required. Further surrogate arguments for credentialing come from recently published literature suggesting that high-volume centres have better outcomes in complex colorectal operations such as pouch surgery [6]. Perhaps in Europe, despite a lack of drive from individual societies, the need for colorectal surgery to be recognized as a speciality may be reflected by the increasing number of applicants for the EBSQ (Coloproctology) Diploma. Nevertheless, difficulties remain in the recognition of the EBSQ examination owing to national health care policies and systems that differ widely from country to country. In most countries the EBSQ (Coloproctology) Diploma is not mandatory nor is it recognized by the national health systems. In some countries, however, the diploma is recognized. For example, in Germany it has been accepted as an equivalent to the German qualification as a visceral surgeon and can serve as a prerequisite for applying for a consultant post in a Centre of Competence in Colorectal Surgery. This probably explains the large number of German diplomates (132) [7]. In Spain, the EBSQ (Coloproctology) Diploma is the exit examination after colorectal surgical training [8].

The EBSQ examination does not test operative skills because training in Europe varies greatly. But is does require evidence of 2 years' training in a colorectal unit and of operative experience. Candidates do not have to have performed the minimum required numbers for all the listed procedures and can compensate by having carried out larger numbers of other procedures. A minimum number of taught index procedures is, however, mandatory to demonstrate a certain level of operative expertise in proctology (haemorrhoids, anal fistula, prolapse) and in colorectal resection (anterior resection, total colectomy) and in stoma formation [4].

In the UK and Ireland, training and certification in general surgery are identical for the two countries including a training programme overseen by the Joint Committee of Surgical Training (JCST), which is an advisory body to the four Royal Colleges of Surgery in the UK and Ireland - Edinburgh, Ireland, England and Glasgow - for all matters related to surgical training in all disciplines. After 2 years of foundation training in the UK ( 1 year in Ireland), the trainee undertakes two initial years of core surgical training and then enters 6 years of speciality training. On completion of surgical training, the trainee is eligible to take the Intercollegiate Board Examination. Candidates must declare a subspeciality interest and are examined in it, but certification is in general surgery. No subspeciality of general surgery is recognized by the UK General Medical Council (GMC). Taken in combination with satisfying the years of training, passing this examination will lead to the award of a Certificate of Completion of Training (CCT) with the consequent addition of the surgeon to the Specialist Register of the GMC (UK) or IMC (Ireland), and that person will then be eligible to apply for a consultant post. It could be interesting in a further study to compare this form of certification and accreditation with that of the EBSQ Diploma.

The Association of Coloproctology of Great Britain and Ireland (ACPGBI) represents 'colorectal surgeons' in the UK and Ireland but is not a credentialing organization. Membership can be obtained only by peer recommendation. A credentialing examination in coloproctology such as the EBSQ one has the potential to strengthen a candidate's appeal as a colorectal surgeon but it is currently purely voluntary. 
The EBSQ coloproctology examination tests not only knowledge and clinical judgement but also the candidate's capacity for critical understanding of the medical literature. The authors believe the academic part, in which the candidate has to read and discuss with the examiners a current published article, is a strong feature of the examination. The open discussion and need to respond to questions covering the entire range of the speciality in the written, oral and academic sections require critical ability and a degree of experience. It has been shown that this type of assessment is a more valid test of knowledge than a multiple-choice test [9]. Continuous ongoing education supporting the ability for critical assessment is essential, as more and more open access journals publish manuscripts, many of which may not have undergone peer review. Assessment by examination not only enhances learning but also helps to gauge knowledge, which is a requisite for competence-based certification programmes [10]. A EBSQ diplomate should be able critically to review articles and draw clinically relevant conclusions to treat patients to the highest standard.

The pass rate of the EBSQ coloproctology examination has been stable over the years at approximately $68 \%$. This high rate suggests that Part 1 of the EBSQ (Coloproctology) process is a valid assessment. Surprisingly, it is not the older candidate who may have performed more surgical procedures but the younger surgeon with some academic training who is more likely to pass. This should encourage the latter to take the examination as soon as the eligibility criteria regarding the number of surgical procedures have been fulfilled. The value of academic training in passing the examination is probably because it is focused on knowledge and critical analysis of the current literature. The analysis showed no difference in pass rate among candidates according to nationality. Most European countries now have a national colorectal society that encourages specialization in colorectal surgery.

The Division of Coloproctology intentionally chose not to use multiple-choice questions for the assessment, preferring the oral examination with its potential advantage for discussion between candidate and examiner. To achieve a fair and standardized examination, the examiners are required to ask predefined questions prompting standard answers. At the same time they are able, through the discussion, to judge the candidate over a wider compass. Importantly the EBSQ coloproctology examination was audited in 2016 and was found to meet UEMS standards [1-3]. It is hoped that the present analysis will attract trainees to apply and obtain the diploma; and in addition will help identify in the eyes of the public and the profession the Division of Coloproctology as the regulating authority in Europe of the competence of colorectal surgeons.

Furthermore, the maturation of our specialization in Europe is rapidly advancing. Promoting and stimulating young colleagues to finalize their training in coloproctology by taking the EBSQ examination should, in our opinion, be highly recommended. Moreover, we call on more senior surgeons to set an example and take the examination in order to advance the level and quality of our speciality.

\section{Conflicts of interest}

The authors declare that they have no competing interests.

\section{Funding}

None.

\section{References}

1 Hahnloser D, Williams JG, Matzel KE. Training colon and rectal surgeons in Europe. Seminars Colon Rectal Surg 2015 ; $26: 150-4$.

2 www.uems.eu

3 www.uemssurg.org/divisions/coloproctology.

4 www.escp.eu.com

5 www.uemssurg.org/divisions/coloproctology/fellow.

6 www.fascrs.org/certification-american-board-colon-and-rec tal-surgery

7 Deutsche Gesellschaft für Allgemein- und Viszeralchirurgie (DGAV). www.dgav.de.

8 Nicholls RJ. Accreditation and certification in Coloproctology in Europe, Acreditación y certificación en Coloproctología en Europa. Cirugía Española 2011; 89: 1-2.

9 Larsen DP, Butler AC, Roediger HL 3rd. Test-enhanced learning in medical education. Med Educ 2008; 42: 95966.

10 Feldman M, Fernando O, Wan M, Martimianakis M, Kulasegaram $\mathrm{K}$. Testing test-enhanced continuing medical education: a randomized controlled trial. Acad Med 2018; 93: S30-6.

\section{Supporting Information}

Additional Supporting Information may be found in the online version of this article:

Appendix S1. Survey sent to all European ESCP representatives. 